\title{
DIFICULDADES DE APRENDIZAGEM E CO- NHECIMENTO: UM OLHAR À LUZ DA TEORIA PIAGETIANA
}

\section{LEARNING DIFFICULTIES AND KNOWLEDGE: A LOOK FROM PIAGET'S THEORY}

Eliane Giachetto SARAVALI*

Karina Perez GUIMARÃES**

Resumo: $O$ artigo apresenta reflexões sobre conceitos importantes da teoria de Jean Piaget e suas implicações para as questões voltadas aos alunos que não aprendem. Discute a rotulação que o termo dificuldade de aprendizagem impõe ao estudante, abordando uma perspectiva desenvolvimentista e construtivista do problema. São apresentadas concepções teóricas a respeito das dificuldades de aprendizagem, bem como considerações sobre olhares diferenciados para essa questão, à luz da teoria piagetiana. Discute-se a importância do conhecimento do psicopedagogo sobre a temática, a fim de que sua atuação não se caracterize pela repetição de rótulos, mas pela consideração dos reais processos percorridos pelos alunos. Esse conhecimento deve ser conseqüência de uma formação sólida que fundamente o futuro profissional, sobretudo, nos momentos de avaliação e intervenção.

Palavras-chave: Dificuldades de aprendizagem. Teoria piagetiana. Psicopedagogia.

* Doutora em Educação pela UNICAMP. Docente do Departamento de Psicologia da Educação da UNESP, Campus de Marília-SP. E-mail: eliane.saravali@marilia.unesp.br

**Doutora em Educação pela UNICAMP, Docente da UniFAIMI, Mirassol-SP. E-mail:

pedagogia@faimi.edu.br 


\begin{abstract}
The article presents reflections about important concepts of Jean Piaget's theory and its implications to issues related to students who do not learn. It discusses the label that the term learning difficulty imposes on students from a development and constructivist approach to the problem. In the article theoretical conceptions concerning learning difficulties are presented, as well as considerations about different views about the issue in the light of Piaget's theory. It discusses the knowledge that the psychopedagogue should have about the problem so that his actions are not characterized by the repetition of labels, but by the consideration of the actual processes experienced by the learners. This knowledge should be the consequence of a solid education that supports the future professional during assessment and intervention periods.
\end{abstract}

Keywords: Learning Difficulties. Piaget's Theory. Psychopedagogy.

\title{
INTRODUÇÃO
}

$\mathrm{Na}$ atualidade, é cada vez mais recorrente falar de dificuldades de aprendizagem, quando o assunto é a aprendizagem de nossos alunos em nossas escolas. Termos como distúrbios, déficits, desordens, bem como explicações sobre incapacidades discentes e rotulações prévias são usados para justificar problemas no rendimento escolar.

Ao mesmo tempo em que o uso dessa terminologia aumenta, cresce também o número de encaminhamentos e de busca por apoio proveniente da ação de outros profissionais que não os próprios professores, tais como: psicólogos, fonoaudiólogos, psicopedagogos, neurologistas, entre outros. Esses fatos são mostrados nos trabalhos de Ciasca (2000) e de Saravali (2005). No primeiro, ao trabalhar com crianças encaminhadas para o ambulatório de distúrbios de aprendizagem da Faculdade de Ciências Médicas da Unicamp, a autora constatou que a grande maioria dos sujeitos encaminhados por 
suas escolas e famílias não apresentava comprometimento cognitivo, perceptivo ou neurológico, ao ser avaliada pela equipe do hospital, ou seja, não apresentava desordens intrínsecas, como sugerem muitas vezes as queixas retratadas nos encaminhamentos. No segundo trabalho referenciado, Saravali (2005) constatou que professores indicam, facilmente, no mínimo $20 \%$ dos seus alunos como tendo dificuldades de aprendizagem.

O papel do psicopedagogo em relação a essas questões cresceu consideravelmente, haja vista que o objeto de estudo da psicopedagogia é o processo de aprendizagem. É importante ressaltar que a formação desse profissional não pode prescindir de estudos teóricos e práticos que fundamentem as ações psicopedagógicas no trabalho voltado para a aprendizagem, seja na escola, na clínica ou em hospitais, tanto num nível remediativo como preventivo.

A qualidade dessa formação se faz mais necessária diante da "epidemia latente" observada a partir dos inúmeros encaminhamentos oriundos da escola e dos docentes. Pela própria especificidade da formação psicopedagógica que deve singularizar a ação desse profissional, é de se esperar que a atuação do psicopedagogo seja balizada por uma visão e postura diferentes, a começar, por exemplo, pela avaliação de um aluno que não aprende. Nesse sentido, vale destacar que o próprio código de ética da psicopedagogia ressalta em seu artigo quinto que é dever do psicopedagogo "promover a aprendizagem, garantindo o bem-estar das pessoas..." Portanto, cabe a esse profissional a investigação e busca constantes sobre razões e intervenções possíveis quando a aprendizagem não caminha bem e isso necessariamente implica uma formação diferenciada. Assim, é imprescindível à formação do psicopedagogo o conhecimento sobre o processo de aprendizagem, como ele ocorre, quais fatores o influenciam, quais as necessidades do sujeito que aprende, bem como quais dificuldades podem ocorrer durante esse processo. Obviamente que, seja sua atuação num nível clínico ou institucional, esse profissional terá que lidar com as questões que envolvem a aprendizagem em situação escolar, incluindo aí as ações didáticas dos docentes.

No presente artigo, buscamos colaborar para a reflexão desse tema analisando as contribuições que a teoria epistemológica de Jean Piaget traz para essas questões. Para isso, discutimos inicialmente um panorama geral a respeito das dificuldades de aprendizagem, destacando diferentes concepções teóricas. Em seguida, são abordados os 
processos cognitivos envolvidos na construção do conhecimento sob a perspectiva piagetiana, fundamentação teórica do presente estudo. A partir disso, discutimos as dificuldades de aprendizagem do ponto de vista teórico escolhido, estabelecendo uma relação entre dificuldades de aprendizagem e psicopedagogia, concluindo que é importante considerar os processos de construção do conhecimento, sendo a teoria piagetiana um aporte a se considerar no trabalho pedagógico e psicopedagógico.

\section{DIFICULDADES DE APRENDIZAGEM - UM PANORAMA GERAL}

Estudar e pesquisar a respeito do termo dificuldades de aprendizagem não é tarefa fácil nos tempos atuais. As caracterizações mais usuais trazem consigo uma série de atributos que acabam ampliando o campo de definição. Assim, observa-se que a definição de dificuldades de aprendizagem pode variar de país para país e de autor para autor.

Dentro dessa variedade terminológica, há autores que buscam uma separação entre o que seria denominado problema, dificuldade ou distúrbio de aprendizagem. É o caso, por exemplo, dos trabalhos de Passeri (2003) e Osti (2004). Neles, as autoras apontam que o termo distúrbio de aprendizagem refere-se mais a comprometimentos neurológicos e que o termo dificuldade de aprendizagem trataria mais de problemas na área acadêmica, decorrentes de fatores internos ou externos ao indivíduo. Segundo Passeri, "este segundo termo é mais genérico, portanto, e envolve os termos 'dificuldade escolar' e 'problemas de aprendizagem" (2003, p.29).

No entanto, essa perspectiva não se confirma em várias outras obras nas quais, muitas vezes, esses termos são tratados como sinônimos; é o caso, por exemplo, do trabalho de Smith e Strick (2001). Uma das poucas certezas que podemos ter em relação a essas definições é que as crianças com dificuldades de aprendizagem não apresentam baixa inteligência, mas sim problemas específicos para aprender. Essa caracterização foi apresentada à comunidade científica por Samuel Kirk, considerado atualmente o pai dos estudos nesse campo. Todavia, cumpre destacar que ao definir o termo, o autor apontava que tais problemas eram provocados, especialmente, por desordens internas 
ou fatores intrínsecos aos indivíduos.

O termo dificuldade de aprendizagem não é recente e há uma evolução histórica que caracteriza as múltiplas influências que os estudos e pesquisas nessa área sofrem. Conforme apresentado em Saravali (2005), essas diferentes perspectivas ora apontam para tendências médicas e orgânicas, ora para tendências psicológicas e pedagógicas, sem, no entanto, haver consenso sobre o que caracteriza uma dificuldade de aprendizagem:

[...] as teorias das dificuldades de aprendizagem são controversas, conceitualmente confusas e raramente apresentam dados de aplicação educacional imediata. Mesmo com uma grande panorâmica e com um grande potencial de investigação, as teorias das DA continuam a ser muito complexas e muito pouco consistentes (FONSECA, 1995, p.57-58).

$\mathrm{Na}$ atualidade, esse panorama não sofreu grandes transformações, mas podemos considerar uma definição datada de 1988, que é muito aceita pelo National Joint Committee on Learning Disabilities. Segundo Sisto (2001), essa definição caracteriza-se da seguinte forma:

1)Problemas nas condutas auto-reguladoras da percepção ou interação social, como por exemplo, déficits de atenção e hiperatividade, (apesar de outros autores discordarem) não constituem uma DA (dificuldade de aprendizagem), embora possam ser sintomas de pessoas com DA.

2)Dificuldades de aprendizagem não se caracterizam por problemas como deficiências sensoriais, retardo mental, transtorno emocional, condições culturais, ensino inadequado ou insuficiente. Entretanto, pode haver coocorrências desses problemas com as DA e “também não se discute que essas condições produzem dificuldades de aprendizagem" (SISTO, 2001, p.13).

3)Dificuldade de aprendizagem corresponde a dificuldades intrínsecas ao indivíduo, supostamente devido a uma disfunção do sistema nervoso central, e estão baseadas em estudos neuropsicológicos e genéticos.

4)Em qualquer idade é possível uma pessoa manifestar DA, o que indica que esse problema pode ser um desafio vitalício.

Assim, poder-se-ia definir que o termo dificuldades de aprendi- 
zagem engloba um grupo heterogêneo de transtornos, manifestando-se por meio de atrasos ou dificuldades em leitura, escrita, soletração e cálculo, em pessoas com inteligência potencialmente normal ou superior e sem deficiências visuais, auditivas, motoras ou desvantagens culturais. Geralmente a DA não ocorre em todas essas áreas de uma só vez e pode estar relacionada a problemas de comunicação, atenção, memória, raciocínio, coordenação, adaptação social e problemas emocionais (SISTO, 2001). O indivíduo com DA não possui rebaixamento de QI, indicando aquilo que muitos autores chamam de conduta discrepante acentuada entre o potencial para a aprendizagem e o desempenho acadêmico.

Embora muitos autores considerem essa definição como a mais completa, não acreditamos que o uso abundante do termo em nossas escolas e por nossos docentes esteja enquadrado nos aspectos previstos pelo Comitê Internacional em questão. Se estivesse, isso significaria o caos em relação à possibilidade de aprender dos nossos estudantes, dada a enorme quantidade de queixas em relação às dificuldades de aprendizagem discentes.

Nesse sentido, concordamos com a posição de Fonseca (1995): para definirmos ou mesmo pensarmos em dificuldades de aprendizagem devemos adotar uma postura interacional e dialética, ou seja, procurar integrar os déficits no indivíduo, na escola, na família, pois “... as condições internas (neurobiológicas) e as condições externas (sócio-culturais) desempenham funções dialéticas (psicoemocionais) que estão em jogo na aprendizagem humana." (1995, p.12).

Dessa forma, o ambiente escolar também pode ser ou não estimulante, oferecendo ou não as oportunidades apropriadas para a aprendizagem:

A fim de obterem progresso intelectual, as crianças devem não apenas estarem prontas e serem capazes de aprender, mas também devem ter oportunidades apropriadas de aprendizagem. Se o sistema educacional não oferece isso, os alunos talvez nunca possam desenvolver sua faixa plena de capacidades, tornando-se efetivamente 'deficientes', embora nada haja de fisicamente errado com eles [...] A verdade é que muitos alunos fracos são vítimas da incapacidade de suas escolas para ajustarem-se às diferenças individuais e culturais (SMITH e STRICK., 2001, p. 33-34). 
É em relação a esses tópicos que gostaríamos de trazer elementos que contribuem para a reflexão. Em nossa experiência cotidiana de formadores de professores e de psicopedagogos, e também na prática clínica, ficamos preocupados com a quantidade de crianças que são colocadas às margens do sistema de ensino, já definidas como incapazes de aprender. Nesse sentido, gostaríamos de abordar o que denominaremos aqui de contribuições da perspectiva construtivista para as dificuldades de aprendizagem. Nosso intuito é mostrar como o estudo e o conhecimento da teoria epistemológica piagetiana, ainda que esse não fosse o objetivo do seu autor (mesmo tendo, em sua obra, reconhecida a importância e a valiosa contribuição para compreensão dos processos de ensino e de aprendizagem), pode trazer referências, sustentabilidade e fundamentação para muitas interpretações, avaliações e intervenções em relação aos problemas para aprender.

\section{PROCESSOS COGNITIVOS ENVOLVIDOS NA CONSTRU- ÇÃO DO CONHECIMENTO}

A construção do conhecimento é explicada por Piaget (1976) como resultado das interações do sujeito com o objeto de conhecimento. Trata-se, portanto, de um novo paradigma que contesta os anteriores, que se limitavam a

indagar se toda a informação cognitiva emana dos objetos e vem de fora informar o sujeito como o supunha o empirismo tradicional, ou se, pelo contrário, o sujeito está desde o início munido de estruturas endógenas que ele imporia aos objetos, conforme as diversas variedades de apriorismo ou de inatismo (PIAGET, 1971, p.13).

O desenvolvimento da criança é concebido por Piaget (1976) a partir do sistema vivo, que é aberto e fechado simultaneamente. Entende-se como sistema aberto as trocas que o organismo estabelece com o meio físico e social; e como sistema fechado a própria constituição do sistema em ciclos. Tais sistemas tendem ao equilíbrio e essa busca está permeada por desequilíbrios e reequilibrações.

Sendo a equilibração o processo central e fundamental na construção do conhecimento, não poderemos deixar de tratar aqui da 
abstração reflexiva e da generalização, mecanismos fundamentais para que a equilibração se dê, ocorrendo, portanto, o avanço de um patamar de conhecimento menos elaborado para outro mais elaborado.

\section{A EQUILIBRAÇÃO}

Ao tratar do desenvolvimento intelectual, Piaget distingue quatro fatores imprescindíveis: a maturação interna, a experiência física, a transmissão social e a equilibração. Esta última é destacada pelo autor como fator fundamental, responsável pelo equilíbrio entre os três outros fatores do desenvolvimento: "a equilibração sendo a compensação por reação do sujeito às perturbações exteriores ..." (1976, p.31).

A construção do conhecimento é explicada por Piaget (1976) pelo processo de equilibração, que consiste na passagem de estados de menor equilíbrio para estados de maior equilíbrio, qualitativamente diferentes. O desencadeamento desse processo ocorre por meio dos desequilíbrios que provocarão reequilibrações, representando o progresso no desenvolvimento do conhecimento.

Os desequilíbrios podem ser resultantes de conflitos momentâneos ou podem ser inerentes à constituição dos objetos ou das ações do sujeito. Pode-se identificar o otimismo do autor (Piaget, 1976), uma vez que o sujeito busca se reequilibrar e superar o desequilíbrio, procurando, assim, uma equilibração majorante.

Nesse sentido, o processo de equilibração independe dos fins almejados pela ação e pelo pensamento e faz com que o sujeito busque novas formas de equilíbrio. Estas, por sua vez, são alcançadas provisoriamente, pois surgem novos problemas, possibilitando ao sujeito construir sobre as formas já existentes.

Desse modo, pode-se afirmar que a aprendizagem modifica a estrutura já existente, como destacou Lima (1984):

não se ensina nada, inteiramente, novo: toda 'aprendizagem' é a modificação de uma estrutura já existente e, por sua vez, modifica a forma de perceber a experiência. Raro é o mestre que indaga o que o aluno já sabe para, sobre esta subestrutura, propor a nova aprendizagem. Nada se aprende a partir da estaca zero! (p.3536). 
Assim, os desequilíbrios têm papel fundamental na medida em que provocam reequilibrações, fazendo com que o sujeito busque sempre uma equilibração majorante, a qual, por sua vez, tem caráter de construção e de maior coerência.

Piaget (1971) destacou o papel da experiência para a construção do conhecimento como estando relacionado ao desencadeamento do processo de equilibração, quando afirma: "o papel da experiência não consiste, em uma primeira fase, senão em desmentir as previsões muito simples fundadas em operações de que dispunha o sujeito e o forçar a procurar previsões mais adequadas" (p.85).

A equilibração majorante resulta de regulações novas, mais ricas que as precedentes devido à abstração reflexiva, um dos motores do desenvolvimento cognitivo. A cada nova realização surgem novas possibilidades inexistentes nos níveis precedentes.

O caráter construtivo do conhecimento fica, assim, evidenciado por Piaget, quando ressalta que:

a construção de estruturas novas parece caracterizar um processo geral cujo poder seria constitutivo e não se reduziria a um método de acessibilidade: dos fracassos do reducionismo causal, no terreno das ciências do real, aos do reducionismo dedutivo quanto aos limites da formalização e às relações das estruturas superiores com as da lógica, assiste-se por toda parte a uma falência do ideal de dedução integral que implica a pré-formação, e isto graças a um construtivismo que aparece cada vez mais (1971, p.107-108).

Para Piaget (1976), os processos de equilibração majorante e seus mecanismos, abstração reflexiva e generalização construtiva, estão intrinsecamente relacionados ao processo de construção dos conhecimentos.

O desenvolvimento cognitivo tem como propriedades as invariantes funcionais: os processos de organização e adaptação, presentes durante toda a vida. Essas propriedades consistem em funções independentes de conteúdo, pois se aplicam a todas as situações. A organização tem como função estruturar o sistema, possibilitando seu funcionamento; a adaptação constitui o equilíbrio entre assimilação e acomodação.

Desse modo, entende-se que a assimilação consiste na integração do elemento novo a um esquema do sujeito. Já a acomodação 
engloba a necessidade de a assimilação considerar as particularidades dos elementos a assimilar, ou seja, é responsável pela modificação das estruturas pré-existentes para ajustar-se ao que lhe é novo.

A atividade assimilativa possui quatro características comuns e presentes em todos os períodos de desenvolvimento: repetição, generalização, diferenciação e reciprocidade.

Para a teoria da equilibração, Piaget (1976) destaca a importância de dois postulados. Quanto ao primeiro, afirma que "todo esquema de assimilação tende a se alimentar, ou seja, incorporar os elementos que são exteriores e compatíveis com sua natureza (...)" (p. 52). Em relação ao segundo postulado, o autor explica que "todo esquema de assimilação é obrigado a acomodar os elementos que assimila, ou seja, modificar-se de acordo com suas particularidades, sem perder a sua continuidade e os poderes de assimilação anteriores" (p.52).

Para que os desequilíbrios possam ser superados e aconteça a equilibração majorante, ocorrem as regulações. Segundo Piaget (1976): “a regulação ocorre quando a repetição A' de uma ação A é modificada pelos resultados desta, logo quando um efeito contrário dos resultados de A sobre seu novo desenvolvimento A' " (p.31). As regulações são, portanto, reações a perturbações.

As regulações provocam as compensações, daí seu caráter construtivo. Como no caso da perturbação, nem toda regulação acarreta uma compensação. Piaget (1976) define compensação como "ação de sentido contrário a um efeito dado, que tende, portanto, para o anular ou neutralizar" (p.40).

A equilibração cognitiva tem como ponto importante seu caráter de ultrapassagem, ou seja, não existe um ponto final; à medida que um conhecimento é alcançado, novos problemas surgem. Nesse sentido, pode-se falar da necessidade de construção e ultrapassagem na busca de um equilíbrio cada vez melhor.

Piaget (1976) ilustra esse caráter construtivo ao afirmar que o mesmo "consiste na elaboração de operações que incidem nas precedentes, de relações de regulações, de regulações de regulações etc., numa palavra, de formas que incidem nas formas anteriores e as englobam como conteúdo" (p.208).

Tal mecanismo, que permite ao sujeito reequilibrar-se por meio de uma reorganização, é a abstração reflexiva. Essa abstração é um dos processos por meio do qual o conhecimento se constrói, pois explica a passagem de um patamar a outro de desenvolvimento. Discorreremos 
mais sobre esse importante conceito da obra piagetiana a seguir.

\section{A ABSTRAÇÃO REFLEXIVA}

Oriunda da coordenação das ações que o sujeito exerce sobre os objetos, a abstração reflexiva centra-se nas operações ou ações gerais do sujeito. Piaget et al. (1995) definem esse tipo de abstração como aquela que se apóia

sobre as formas e sobre todas as atividades cognitivas do sujeito (esquemas ou coordenações de ações, operações, estruturas etc.) para delas retirar certos caracteres e utilizá-los para outras finalidades (novas adaptações, novos problemas etc.) (p.06).

Há dois aspectos inseparáveis envolvendo a abstração reflexiva. De um lado, o "reflexionamento", como projeção (no sentido de espelhar) num patamar superior a aquilo que foi tirado do patamar inferior. De outro lado, a "reflexão", enquanto ato mental de reconstrução e reorganização sobre o patamar superior daquilo que foi transferido do inferior.

No momento em que o sujeito consegue fazer coordenações, sem, no entanto, vê-las nos objetos, tem-se a abstração refletida. É, portanto, resultante de uma abstração reflexiva quando esta se torna consciente, independente do nível em que está.

Os reflexionamentos, no sentido de projeção, diferenciam-se conforme seu grau e natureza. Os patamares mais elementares dos reflexionamentos partem das ações sucessivas em direção a sua representação atual, isto é, do sensório-motor ao início da conceituação. Em um segundo patamar, as representações são reunidas num todo coordenado; trata-se da "constituição (com ou sem narrativa) da seqüência das ações, do ponto de partida ao término" (PIAGET et al., 1995, p.275). O terceiro patamar corresponde ao das comparações, podendo ser reconstituída a ação como um todo e comparada a outras que podem ser análogas ou diferentes. Finalmente, no quarto patamar, encontram-se as reflexões sobre as reflexões caminhando para a meta-reflexão ou pensamento reflexivo.

A natureza dos reflexionamentos, inicialmente, consiste num “deslocamento dos observáveis em função de sua conceituação progressiva pela tomada de consciência, isto é, pela interiorização das 
ações" (PIAGET et al., 1995, p. 276).

Patamares posteriores englobam, em sua maior parte, a abstração como se fosse reflexão, já que a generalização possibilita o reflexionamento dos observáveis de patamares anteriores sobre os novos. Pode-se dizer, dessa forma, que existe uma diferença de grau e também qualitativa em todo novo patamar, ficando à união da reflexão e do reflexionamento não somente a responsabilidade da passagem de patamares, mas também a própria formação dos mesmos.

Trata-se, portanto, de um processo espiral que busca formas cada vez mais elaboradas, como afirmam Piaget et al. (1995):

Todo reflexionamento de conteúdos (observáveis) supõe a intervenção de uma forma (reflexão), e os conteúdos assim transferidos exigem a construção de novas formas devido à reflexão. Há, assim, pois, uma alternância ininterrupta de reflexionamentos $\rightarrow$ reflexões $\rightarrow$ reflexionamentos; e (ou) de conteúdos $\rightarrow$ formas $\rightarrow$ conteúdos reelaborados $\rightarrow$ novas formas, etc., de domínios cada vez mais amplos, sem fim e, sobretudo, sem começo absoluto (p.277).

A partir da tomada de consciência de uma certa ação ou operação concreta, o sujeito poderá refletir e projetar em um novo plano decorrente do precedente, generalizando e superando as estruturas anteriores. É nesse sentido que os processos de generalização construtiva intervêm na elaboração do conhecimento.

A evolução psicogenética das generalizações explica a construção do conhecimento exógeno por uma construção endógena, por meio dos níveis de tomada de consciência. Num primeiro momento, o sujeito, interagindo com os objetos, somente registra os observáveis dos mesmos como sendo resultados exteriores da ação, devido à abstração reflexiva. Em seguida, ocorre o desenvolvimento material da ação e das variações do objeto de forma mais numerosa, podendo reunir-se entre elas. Por fim, a tomada de consciência das coordenações internas das ações possibilita o conhecimento das propriedades menos imediatas dos objetos, resultantes dos processos de abstração reflexiva.

Falar em aprendizagem a partir dessa teoria é falar, portanto, em algo que estruturalmente depende do desenvolvimento, mas que ao mesmo tempo contribui para que ele ocorra. A aprendizagem se insere nesse conceito de inteligência adaptativa e em construção. 
Se a escola, os professores e os psicopedagogos lidam, prioritariamente, com a aprendizagem, não podem estar alheios a tais conhecimentos. Será que no âmbito pedagógico e psicopedagógico são discutidas as formas de atuação que privilegiam, respeitam e caminham ao encontro dos processos percorridos pelos alunos durante a aprendizagem? E quando um aluno apresenta dificuldades de aprendizagem? Como as questões teóricas que tratamos anteriormente podem contribuir para a compreensão dessa problemática? Qual seria, a partir do exposto, a relação da teoria piagetiana com as questões referentes às dificuldades de aprendizagem?

\section{DIFICULDADES DE APRENDIZAGEM - UM OLHAR CONS- TRUTIVISTA}

Assumindo a perspectiva interacionista-construtivista de Jean Piaget, diferentes autores identificam os problemas de aprendizagem como resultantes de falhas no processo de relação do sujeito com o meio, pressuposto básico do interacionismo-construtivista. Dessa forma, a pergunta que esses autores querem responder, ao se depararem com crianças que não aprendem, é "o que ocorre com as crianças que não atuam sobre o meio, por serem impedidas, ou atuam pouco?" (DOLLE e BELLANO, 1996, p.9). Ramozzi-Chiarottino, que realiza pesquisas nesse enfoque, explica:

Depois de vários anos de observação do comportamento da criança em situação natural, chegamos à conclusão de que os distúrbios de aprendizagem são determinados por deficiências no aspecto endógeno do processo da cognição e de que a natureza de tais deficiências depende do meio no qual a criança vive e de suas possibilidades de ação neste meio, ou seja, depende das trocas do organismo com o meio, num período crítico de zero a sete anos (1994, p.83).

Assim, para essa autora, há uma causa orgânica para as DA, parcialmente determinada pelo ambiente e possível de remediação. Nos estudos e pesquisas que realiza na USP, Ramozzi-Chiarottino (1994) apresenta características e problemas específicos no processo de interação com o meio e na estruturação do real, que as crianças 
com dificuldades de aprendizagem apresentam.

Os psicopedagogos e demais interessados na questão das dificuldades de aprendizagem necessitam conhecer esse referencial que, ao contrário do que Fonseca (1995) afirma sobre outras perspectivas, possui aplicação educacional imediata. Nesse sentido, Ramozzi-Chiarottino (1994) apresenta formas de intervenção conforme as características dos problemas apresentados pelas crianças. Essas intervenções baseiam-se em: construção de esquemas motores e ação/reflexão sobre o meio, observação e experimentação sobre a natureza, construção de representação e construção de estruturas do pensamento.

A respeito dessa última intervenção, é importante destacar que diferentes pesquisas, baseadas em tal pressuposto, alcançaram bons resultados com crianças que apresentavam dificuldades de aprendizagem. É o caso dos trabalhos de Brenelli (1996, 2002), Souza (1996), Zaia, (1996), Guimarães (1998, 2004) e Fini (2002). Os resultados dessas pesquisas apontam que alunos com queixa de dificuldade de aprendizagem, quando têm a oportunidade de interagir com um meio profícuo e solicitador, que os auxilie na construção de suas estruturas da inteligência, apresentam significativa melhora em seu desempenho escolar. Esse meio, que é profícuo e solicitador, caracteriza-se pela elaboração de atividades, pela utilização de jogos e pela criação de situações de trocas e cooperação que provocavam a ação e a construção do conhecimento por parte dos sujeitos.

Os trabalhos sob essa perspectiva indicam que aqueles que lidam com as crianças em situações de aprendizagem necessitam estar atentos ao que está ocorrendo com seus alunos. Portanto, é preciso investigar por que as crianças não aprendem, mas, sobretudo, é preciso saber quais são os meios de que a escola pode se valer para minimizar as condições de fracasso que são impostas a esses alunos. Assim, é sempre bom refletir sobre as razões que levam a escola ao encaminhamento, em comparação com as intervenções que conseguem resultados positivos em situações de pesquisa. Qual o papel dos profissionais que lidam diretamente com essas crianças? Como eles vêem essas questões e quais as formas de intervenção que julgam necessárias e importantes de serem feitas? 


\section{PSICOPEDAGOGIA E TEORIA PIAGETIANA}

Em estudo recente, Guimarães e Saravali (2006) investigaram as concepções de alunos do curso de psicopedagogia a respeito das dificuldades de aprendizagem. As autoras trabalharam com 52 sujeitos que estavam no início, no meio e no final do curso de especialização; a maioria deles era docente da educação infantil e das séries iniciais do ensino fundamental. Os principais resultados encontrados indicaram que $56 \%$ dos futuros psicopedagogos acreditam que a dificuldade de aprendizagem refere-se sempre e somente a uma incapacidade do sujeito que não aprende; $46 \%$ deles sentem-se incapazes diante do quadro de um aluno que não aprende e não sabem intervir, necessitando recorrer a atendimentos especializados; e 33\% descrevem alunos com dificuldades de aprendizagem como aqueles que possuem problemas relacionados aos conteúdos abordados em sala de aula, principalmente matemática e leitura e escrita.

Dois aspectos chamam a atenção na fala desses futuros profissionais: primeiramente, a quantidade de justificativas para o problema no próprio aluno; e segundo, a incapacidade para a intervenção. Não seria justamente a falta de uma formação mais sólida que traria esse tipo de julgamento? Por que as razões para a não aprendizagem são sempre depositadas nos alunos? Por que a necessidade de outros profissionais é quase sempre lembrada, mesmo quando a criança não está aprendendo, por exemplo, a ler e a escrever, conteúdos de responsabilidade da escola? Ou será que vivemos mesmo uma epidemia escolar?

Acreditamos que o estudo e o aprofundamento numa teoria como a piagetiana podem auxiliar e muito na formação do psicopedagogo. Ao atuar na clínica ou na instituição, esse profissional precisa refletir sobre as condições de construção do conhecimento que estão sendo ofertadas aos alunos. Desse modo, partindo-se da concepção construtivista piagetiana, o ensino deveria orientar-se para as potencialidades, limitações, erros e ações dos alunos, pois o conhecimento vai se construindo junto com e pelo sujeito.

O aluno é, portanto, considerado sujeito dos processos de ensino e de aprendizagem, sendo totalmente ativo nessa construção. Essa perspectiva construtivista vem opor-se à concepção empirista do conhecimento, que considera a aprendizagem como aquisição do conhecimento pronto, externo ao sujeito, sendo realizada basicamente 
pela repetição e memorização. Como ilustra Ferreiro (2001):

Piaget opõe uma concepção segundo a qual o objeto não está dado no ponto de partida, mas se constrói a partir de um organismo que não é criado pelo sujeito, mas que é a condição mesma de sua existência; a evidência racional não é produto direto da experiência nem uma forma a priori do espírito: é o resultado de processos de reequilibração sucessivos, em virtude de um processo histórico e dialético; a objetividade não está dada no ponto de partida: é uma realização, uma conquista, não um impor-se do objeto sobre o sujeito, mas um equilíbrio entre ambos, que envolve um máximo de atividade da parte do sujeito, um sujeito que é sempre ator e nunca mero espectador (p.138).

De acordo com essa perspectiva, os fundamentos de uma avaliação e de uma intervenção - seja num nível clínico ou institucional, de forma preventiva ou remediativa - terão que, necessariamente, considerar as possibilidades de interação com os objetos de conhecimento que o sujeito teve ou tem. De que forma a ação sobre os objetos, a possibilidade de organização, de estabelecimento de relações, de assimilações, acomodações e equilibrações vêm sendo promovidas, solicitadas ou desencadeadas? Quantos desequilíbrios o sistema cognitivo dessa criança que não aprende teve a chance de responder? Ou somente lhe foi solicitado repetir, sem compreender? Quantos desencadeamentos são feitos no sentido de se fornecer a projeção e a reflexão?

Partindo dessa concepção teórica, o papel da escola - e vale a pena frisar que o psicopedagogo tanto clínico como institucional tem que lidar com as questões escolares também - deveria voltar-se ao oferecimento de desafios à criança, a fim de provocar o desencadeamento do processo de construção do conhecimento. Nesse sentido, a escola precisa ter clara a concepção de conhecimento e a compreensão dos processos de aprendizagem que possibilitam a produção de novos conhecimentos.

Piaget (2000) definiu o conhecimento como sendo essencialmente construção, ao afirmar que:

O caráter próprio da vida é ultrapassar-se continuamente e, se procurarmos o segredo da organização racional na organização vital, inclusive em suas superações, o método consiste então em procu- 
rar compreender o conhecimento para sua própria construção, o que nada tem de absurdo, pois o conhecimento é essencialmente construção (p. 409).

O conhecimento, portanto, não deve ser entendido como exterior ao sujeito, trazido pelo professor, mas sim como um processo dialético que emerge do próprio sujeito, de acordo com suas diferentes formas de agir sobre o mundo. Segundo essa concepção, a aprendizagem passa a ter, além da capacidade de assimilar conteúdos, a capacidade de transformar, ou seja, de construir novas formas possíveis de assimilá-los. A aprendizagem ocorre em função do desenvolvimento, de esquemas e estruturas construídas, que se generalizam conforme se aplicam ativamente as novas formas.

Para que ocorra uma reorganização com novas combinações de elementos retirados do nível anterior, o sujeito utiliza o mecanismo de abstração reflexiva com seus aspectos inseparáveis de "reflexionamento", como projeção (no sentido de espelhar) sobre um patamar superior do que foi retirado do nível inferior, e de "reflexão" enquanto ato mental de reorganização e reconstrução sobre o patamar superior. O desenvolvimento da abstração reflexiva ocasiona a formação de novas formas em relação aos conteúdos.

Juntamente com a abstração reflexiva, o mecanismo de generalização tem papel fundamental na elaboração do conhecimento, uma vez que a partir da tomada de consciência o sujeito poderá refletir e projetar em um novo plano decorrente do anterior, generalizando e superando as estruturas anteriores. Dessa forma, os processos de generalização construtiva intervêm junto à abstração reflexiva na elaboração do conhecimento.

Para que isso ocorra, as atuações didáticas precisam promover a ação por parte do sujeito que aprende, solicitar a reorganização da ação, a reflexão sobre a ação, as antecipações e a análise das conseqüências sobre as ações.

Uma das possibilidades à disposição do educador e do psicopedagogo pode ser encontrada na utilização de jogos de regras que, além de favorecer a construção do pensamento, possibilita intervenções que maximizam a aprendizagem dos alunos. Brenelli (1999) destaca que:

as crianças muitas vezes apresentam resistências às atividades, 
o jogo pode ser utilizado como meio de vencê-las, porque nele a motivação e o interesse são intrínsecos. Entretanto, é necessário que o educador conheça e saiba aproveitar as oportunidades que um contexto lúdico tem (p.71).

Os jogos exercem papel fundamental no desenvolvimento da criança. Macedo, Petty e Passos (2000) corroboram essa idéia, ao explicitarem que:

Quando a criança joga e é acompanhada por um profissional que propõe análises de sua ação, descobre a importância da antecipação, do planejamento e do pensar antes de agir. Por sentir-se desafiada a vencer, aprende a persistir, aprimora-se e melhora seu desempenho, não mais apenas como uma solicitação externa, mas principalmente como um desejo próprio de autosuperação (p.25).

Os jogos de regras serviram de inspiração para muitos trabalhos fundamentados na teoria psicogenética de Piaget. Esses trabalhos identificaram os jogos como auxiliares na compreensão da estruturação cognitiva das crianças e no favorecimento de processos construtivos do pensamento e da aprendizagem (BRENELLI, 2002)

Os processos de equilibração, abstração reflexiva e generalização construtiva podem estar presentes nas situações de jogo, sendo que a abstração reflexiva conduz a generalizações construtivas, fundadas nas operações dos sujeitos. Sua natureza, simultaneamente extensiva e compreensiva, pode gerar novas formas, até mesmo novos conteúdos. Desse modo, é via abstração reflexiva que os sujeitos podem passar para um plano novo, no qual reorganizam o que foi trazido do anterior.

As perturbações são fundamentais na medida em que há compensação pelo sujeito como forma de regulação, ou seja, a reação à perturbação é fundamental para o desenvolvimento. O jogo de regras pode representar uma perturbação para a criança e contribuir assim para seu desenvolvimento, como afirma Brenelli:

Quando a criança modifica sua maneira de jogar ou modifica seus procedimentos nas atividades propostas durante o jogo significa que as perturbações não foram anuladas, mas compensadas, na tentativa de se acomodarem às situações exigidas pelo jogo (1996, p.161). 
A invenção de novos procedimentos para ter mais êxito no jogo viabiliza a construção de possibilidades e necessidades. Esse aspecto remete-nos à construção de novas possibilidades, o que depende da equilibração e da relação entre a abstração reflexiva e a generalização construtiva, uma vez que a abstração reflexiva conduz à generalização construtiva, conforme discutimos anteriormente.

A partir do exposto, qual seria então o papel da psicopedagogia? Podemos afirmar que o principal foco deveria ser o de resgatar a possibilidade de desencadeamento desses processos cognitivos tratados até aqui, seja por meio de jogos, de atividades ou outros procedimentos oportunos. Uma vez que a escola não está dando conta desses aspectos, a psicopedagogia institucional ou clínica poderia dedicar-se à criação desse meio solicitador.

Cabe aqui mais uma reflexão em relação ao papel ativo da criança ao se deparar com situações de aprendizagem. A rotulação prévia, que em larga escala vem ocorrendo em nossas escolas, a nosso ver caracteriza-se pela não compreensão do conhecimento como processo de construção. Num extremo temos a rotulação, que define a dificuldade de aprendizagem com algo inerente ao sujeito, intrínseco, normalmente definido como um transtorno ou uma incapacidade duradoura. De outro, é bem verdade, pode-se cair no risco de sempre culpar os docentes pela não aprendizagem discente, como se bastassem as experiências provenientes do meio, o que se constituiria como uma forma empirista de explicar o fenômeno. No entanto, percebe-se que quando as explicações para uma não aprendizagem não recaem somente sobre incapacidades cognitivas do aluno, recaem sobre sua família ou sobre questões emocionais e afetivas (GUIMARÃES e SARAVALI, 2006).

No campo de atuação psicopedagógica institucional escolar, poderíamos nos perguntar: Em que medida as questões pedagógicas relacionadas ao respeito pelos processos de aquisição do conhecimento vêm sendo debatidas ou são de domínio dos responsáveis pela aprendizagem dos alunos? Num nível de atuação clínica, como as avaliações e intervenções psicopedagógicas vêm conseguindo considerar esses aspectos, buscando auxiliar aquele que não aprende a ter uma nova chance de se relacionar com seu objeto de conhecimento de forma construtiva? 


\section{CONSIDERAÇÕES FINAIS}

O que se pretendeu neste artigo foi oferecer algumas ferramentas para a reflexão daqueles que lidam com a aprendizagem e, conseqüentemente, com as dificuldades de aprendizagem.

Como vimos, pesquisas que tomam por referência a teoria piagetiana conseguem bons resultados em situação de intervenção pedagógica e psicopedagógica junto a crianças que não aprendem. Nessas pesquisas, aspectos essenciais ao desenvolvimento infantil são resgatados e os alunos passam a ter uma nova relação com seus objetos de conhecimento.

Diante do quadro crescente de crianças avaliadas como incapazes de aprender e do grande aumento do número de encaminhamentos, a perspectiva abordada aqui nos traz um novo olhar para uma situação de dificuldade de aprendizagem.

Os psicopedagogos, que estão sendo cada vez mais solicitados a resolverem e a participarem dessas questões, precisam estar preparados para terem um novo olhar, muitas vezes diferente daquele que a escola já lança sobre o aluno que tem dificuldades de aprendizagem. Esse olhar psicopedagógico investigativo deve conhecer como o aluno pensa e aprende, analisar esses processos ao longo da vida discente e buscar reorganizá-los num novo momento e numa participação mais ativa do discente.

Quando o psicopedagogo ou mesmo os docentes em sala de aula não sabem intervir, isso pode significar o abandono daquele que não aprende ou ainda a rotulação prévia, que também abandona e exclui, além de isentar de responsabilidades os que podem ajudar na promoção da aprendizagem.

Enfim, ao final deste trabalho, sabendo que muitas questões continuam abertas à discussão e à pesquisa, concluímos que, como educadores, psicopedagogos ou pesquisadores, necessitamos levar em consideração os processos inerentes à construção do conhecimento. E a teoria piagetiana é, certamente, um aporte que precisa ser considerado.

Queremos encerrar com uma fala de Castro (2001, p. 19), que retrata a importância de repensarmos os processos de ensino e de aprendizagem: 
Devemos, pois, redefinir conceitos e pensar em termos novos, ou melhor, em significações diferentes para os termos tradicionais da didática - o aluno, o professor, o que se ensina, como se ensina, por que e para que ensinar - formulando novos conceitos sobre tais elementos didáticos. Tal redefinição poderá exigir um novo conceito de "conteúdo", que não será apenas matemática, história ou geografia, ou dos objetivos atribuídos à escola. Dar-se-ia mais importância a atividades que ensinem a pensar ou a incentivar o uso do pensamento pelo aluno. O ensino não se confundiria com a aquisição de informações, mas com a construção de conhecimento e com o desafio ao pensamento. A teoria, que espero seja um dia formulada, poderá ajudar o professor se conseguir deixar claros os princípios nos quais se baseia: os mesmos do construtivismo piagetiano. Deixamos a sugestão para quem se interessar por ela (grifo nosso).

\section{REFERÊNCIAS}

ASSOCIAÇÃO BRASILEIRA DE PSICOPEDAGOGIA. Código de Ética. Disponível em: http://www.abpp.com.br/leis_regulamentacao_etica.htm. Acesso: 31 jan. 2007.

BRENELLI, R. P. O jogo como espaço para pensar. Campinas: Papirus, 1996. 208p.

.Jogos de regras em sala de aula: um espaço para construção operatória. In: SISTO, F. F. (Org.). O cognitivo, o social e o afetivo no cotidiano escolar. Campinas: Papirus, 1999. p. 69-88.

.Espaço lúdico e diagnóstico em dificuldades de aprendizagem: contribuição do jogo de regras. In: SISTO, F.F. (Org.). Dificuldades de aprendizagem no contexto psicopedagógico. 2. ed. Petrópolis: Vozes, 2002. p. 167-189.

CASTRO, A. A. D. Educação e Epistemologia Genética. In: MANTOVANI DE ASSIS, O. Z. et al. (Org.). Um olhar construtivista sobre a educação. Campinas: Vieiras, 2001. p. 9 -20.

CIASCA, S.M.; ROSSINI, S.D.R. Distúrbio de aprendizagem: mudanças ou não? Correlação de dados de uma década de atendimento. Temas sobre Desenvolvimento, v. 8, n. 48, p. 11-6, 2000.

DOLLE, J.; BELLANO, D. Essas crianças que não aprendem - diagnósticos e terapias cognitivas. Tradução: Cláudio Saltini e Lia Leme Zaia. Petropólis: Vozes, 1996. 195p. Título original: Ces enfants Qui n’apprennent pas: 
diagnostic et remédiations.

FERREIRO, E. Atualidade de Jean Piaget. Tradução de Ernani Rosa. Porto Alegre: Artes Médicas, 2001. 143 p.

FINI, L.D.T. Aritmética no ensino fundamental: análise psicopedagógica.In: SISTO, F.F. (Org.). Dificuldades de aprendizagem no contexto psicopedagógico. Petrópolis: Vozes, 2002. p. 60-78.

FONSECA, V. Introdução às Dificuldades de Aprendizagem. 2. ed. rev. e aum. Porto Alegre: Artes Médicas, 1995. 388p.

GUIMARÃES, K.P. Abstração reflexiva e construção da noção de multiplicação via jogos de regras: em busca de relações. 1998. 181f. Dissertação (Mestrado em Educação). Faculdade de Educação, Universidade Estadual de Campinas, Campinas, 1998.

.Processos cognitivos envolvidos na construção das estruturas multiplicativas. 2004. 197f. Tese (Doutorado em Educação) - Faculdade de Educação, Universidade Estadual de Campinas, Campinas, 2004.

GUIMARÃES, K.P.; SARAVALI, E.G. Concepções dos alunos do curso de psicopedagogia a respeito das dificuldades de aprendizagem. Educação Temática Digital, v. 8, n. 1,p. 187-207, dez 2006.

LIMA, L. A construção do homem segundo Piaget: uma teoria da Educação. São Paulo: Summus, 1984. 149 p.

MACEDO, L.; PETTY, A. L. S.; PASSOS, N. C. Aprender com jogos e situações-problema. Porto Alegre: Artes Médicas, 2000. 116 p.

OSTI, A. As dificuldades de aprendizagem na concepção do professor. 2004. 149f. Dissertação (Mestrado em Educação) - Faculdade de Educação, Universidade Estadual de Campinas, Campinas, 2004.

PASSERI, S.M.R.R. O autoconceito e as dificuldades de aprendizagem no regime de progressão continuada. 2003. 179f. Tese (Doutorado em Educação) - Faculdade de Educação, Universidade Estadual de Campinas, Campinas, 2003.

PIAGET, J. Para onde vai a educação? Tradução Ivette Braga. Rio de Janeiro: Livraria José Olympio, 1971. 80 p. (Ed. Original: 1948).

.A equilibração das estruturas cognitivas: problema central do desenvolvimento. Tradução de Marion M. dos S. Penna. Rio de Janeiro: Zahar, 1976. 228 p. (Ed. original: 1975).

.Biologia e Conhecimento. Tradução de Francisco M. Guimarães. 3. ed. Petrópolis: Vozes, 2000. 423 p. 
PIAGET, J. et al. Investigaciones sobre la generalización. México: Premia, 1984. $220 \mathrm{p}$.

PIAGET, J. et al. Abstração reflexionante: relações lógico-elementares e ordem das relações espaciais. Tradução Fernando Becker e Petronilha B. G. da Silva. Porto Alegre: Artes Médicas, 1995. 292 p. (Ed. original 1977).

RAMOZZI-CHIAROTTINO, Z. Em busca do sentido da obra de Jean Piaget. 2. ed. São Paulo: Ática, 1994. 118p.

SARAVALI, E.G. Dificuldades de Aprendizagem e Interação Social - implicações para a docência. Taubaté: Cabral, 2005. 156p.

SISTO, F. Dificuldades de Aprendizagem. In: SISTO, Fermino et al. Dificuldades de aprendizagem no contexto psicopedagógico. 2. ed. Petrópolis: Vozes, 2001. p. 19-39.

SMITH, C.; STRICK, L. Dificuldades de Aprendizagem de A a Z - um guia completo para pais e educadores. Tradução: Dayse Batista. Porto Alegre: Artmed, 2001. 332p. Título original: Learning Disabilities: A to Z - a parent's complete guide to learning disabilities from preschool to adulthood.

SOUZA, M. T. C. Intervenção psicopedagógica: como e o que planejar? In: SISTO, F.F. (Org.). Atuação Psicopedagógica e aprendizagem escolar. Petrópolis: Vozes, 1996. p.113-126.

ZAIA, L. L. A solicitação de meio e a construção das estruturas operatórias em crianças com dificuldades de aprendizagem. 1996. 255f. Tese (Doutorado em Psicologia Educacional) - Faculdade de Educação, Universidade Estadual de Campinas, Campinas, 1996.

Encaminhado em: 16/03/07

Aceito em: 24/05/07 